\title{
O fortalecimento da igualdade de gênero no ambiente de trabalho: um diálogo entre o estado democrático de direito e os direitos humanos
}

Viviane Bastos Machado

Emilly de Figueiredo Barelli
Mestre em Cognição e Linguagem - UENF. E-mail: vivianembastos@hotmail.com

Acadêmica do curso de Direito - Faculdade Metropolitana São Carlos.

E-mail: emillybah2014@gmail.com

Recebido em: 30 jan.. 2017. Revisado: 25 abr. 2017. Aceito: 05 set. 2017.

DOI: http://dx.doi.org/10.21674/2448-0479.33.472-494

\section{Resumo}

Destaca-se nesse momento a existência de uma construção legislativa formalizada no intuito de efetivar a realidade de um direito que se constrói a tempos, e que efetivamente está ainda em formação. Encontrar as melhores e as mais eficientes ferramentas para efetivar a existência da igualdade não é tarefa simples, nem muito menos, perde complexidade pelo momento em que estamos vivendo. A etapa de construção da realidade feminina perpassa por mecanismos de preconceito velado, e de uma economia avassadora, do ponto de vista de suas exigências nos dias que atualmente vivenciamos. Impressiona-se ao constatar que a quantidade de mulheres 
que ainda são relegadas a determinados cargos, e outras que sequer atingem o valor econômico decorrente ao seu cargo, em igualdade de condição com homens é comum. A proposta é, através de uma revisão de literatura, levantar questões humanas, históricas, legais, jurídicas, assim sendo, propõe-se nesse trabalho fazer um levantamento de algumas normas legais que buscam atingir a expectativa constitucional do princípio da igualdade através de ferramentas e, especialmente, todos os questionamentos se direcionam a realidade laboral da mulher na realidade brasileira.

Palavras-chave: Mulher. Dignidade humana. Igualdade laboral.

\section{Abstract \\ Strengthening gender equality in the work- place: a dialogue between the democratic state of law and human rights}

It stands out at that moment the existence of a formalized legislative construction is not intended to effect a reality of a law that is built a times, and that is actually still in formation. Finding the best and most efficient tools for effecting the existence of equality is no simple task, let alone losing complexity when you are living. A stage of the construction of the feminine reality runs through mechanisms of veiled prejudice, and of an overpowering economy, make the point of view of their demands in the days that we live. It is surprising to note that a number of women who are still relegated to certain positions, and others who do not even reach the economic value of their burden, on equal terms with ordinary men. The proposal is, through a literature review, to raise human, historical, legal and juridical issues, so it is proposed in this paper to make a survey of some legal norms that 
seek to achieve a constitutional expectation of the principle of equality through tools and Especially, all the questions are directed to a woman's labor reality in Brazilian reality.

Keywords: Woman. Human dignity. Labor equality.

\section{Introdução}

A presença significativa da mulher no mercado de trabalho brasileiro tem sido vital para que se fortaleça a igualdade de gênero no ambiente laboral. A ocupação de cargos que anteriormente eram funções exercidas apenas pelo sexo masculino, garante à mulher a possibilidade de uma exitosa carreira profissional, em meio ao Estado Democrático de Direito.

As mulheres brasileiras que em tempos não muito distantes, como no início do século $X X$, exerciam restritivamente funções de cunho exclusivamente doméstico ou atividades rurícolas, de forma equivocada eram classificadas como inativas economicamente sendo ocultada sua contribuição em dados trabalhistas. Entretanto, hodiernamente, a força da mulher brasileira mostra-se em posição de destaque em meio a crises econômicas enfrentadas pelo país. $\mathrm{Na}$ busca por uma complementação da renda familiar e na expectativa de maiores fontes de consumo, o gênero feminino fez-se presente em trabalhos fora do âmbito doméstico assumindo cargos, empregos e funções que garantem com sucesso, o orçamento de suas famílias.

Isto posto, cabe analisar a mudança do paradigma comportamental feminino. Certo de que, já não são vinculados à mulher ultrapassados valores sociais como a obrigatoriedade da maternidade, 0 
excessivo número de filhos, a servidão ao seu companheiro, a ausência dos direitos políticos, ou até mesmo a obediência a dogmas religiosos. Atualmente, estão abertas possibilidades de acesso à educação, desde os estudos basilares como também o ingresso em conceituadas universidades, propiciando desta forma, o aumento da presença feminina no mercado de trabalho.

Neste ínterim, cabe estabelecer um diálogo entre o Estado Democrático de Direito e os Direitos Humanos que norteiam a posição atual da mulher no ambiente de trabalho, abordando questões de cidadania em processos político-sociais.

Com fulcro na Lei Maior e na realidade fatídica atual, insta analisar o processo evolutivo do trabalho e da ocupação das brasileiras, evidenciando e compreendendo as principais transformações pelas quais estas passaram, além de expor legislações que possibilitaram tais avanços femininos.

O presente trabalho, desenvolveu-se através de revisão de literatura, qualitativa, objetivando a reconstrução de momentos fundamentais sobre a efetividade de resguarda à mulher cidadania, especialmente nas atividades laborais e sociais.

\section{A evolução social e política de proteção legal do tra- balho da mulher}

Em 15 de outubro de 1827, surgia o ensino primário para 0 sexo feminino, restrito a determinadas classes e, com objetivo limitado a organização da vida doméstica. Eram ensinadas técnicas voltadas para a economia doméstica, costura, decoração e pintura, induzindo assim o desenvolvimento de funções "classificadas" como femininas. Além disso, Silva (1974, p.3) afirma que também haviam indícios de particulares que ensinavam em suas casas estas supra- 
citadas funções. Mesmo com o acesso a cursos de nível superior, em 1879, ainda assim à mulher era restrita a ocupação de carreiras médicas ou jurídicas.

Mesmo com a abolição da escravatura, em 1888, a mulher permanecia vista como uma classe explorada em meio à sociedade. A escassez de uma educação formal impossibilitava sua profissionalização acarretando em alguns casos a marginalização e prostituição como meios de sobrevivência.

Através da Revolução de 1930, surge a era dos Direitos Trabalhistas, relata o autor Costa (2013, p. 20). Nesta, o Ministro Lindolfo Collor expede a primeira lei a versar sobre a situação da mulher trabalhadora, o Decreto 24.417-A de 1932, norma de fundamental relevância não por sua produção legal em si, mas pela simbologia da necessidade de regulamentar e possibilitar avanço à mulher na área laboral. Esta norma, garantia proteção contra a acentuada exploração social sofrida pelo sexo feminino no ambiente laboral.

A gênese da industrialização não facilitou, a princípio, o desenvolvimento do trabalho feminino. Haviam diversos setores que restringiam radicalmente a mão-de-obra feminina de forma a propiciar uma segregação sexual trabalhista. Entretanto, mesmo que outros setores permitissem seu trabalho, como por exemplo o setor fabril, a mulher era proibida de sair de casa para trabalhar. Ficando assim restrita, conforme Calil $(2007$, p.1) a costuras feitas no âmbito doméstico.

Com o desenvolvimento da normatização do trabalho, foram favorecidos apenas trabalhadores do sexo masculino, havendo uma injusta dispensa da força laboral feminina. Com isto, elas apenas conseguiam trabalho em lugares menos favorecidos nos quais não havia regulamentação que as protegessem. 
Em riqueza de detalhes, Barros (1995, p. 245, 297, 298) apresenta a evolução dos direitos da mulher no ambiente laboral e afirma que em 29 de dezembro de 1917, surge a primeira legislação direcionada à mulher operária no Estado de São Paulo. A lei de no 1.596, instituiu o Serviço Sanitário do Estado, garantindo a vedação ao trabalho no último mês de gravidez e no primeiro após o período de resguardo. A Regulação do Departamento Nacional de Saúde Pública (Decreto № 16.300, de 1923) garantia às empregadas em estabelecimentos industriais e de comércio um repouso de 60 dias, sendo 30 antes do parto, e o restante após este. Além disso, era possível que as empregadas amamentassem seus filhos, porém havia omissão no que tange ao tempo de duração do intervalo para a amamentação.

Cabe salientar que, de acordo com a Organização Internacional do Trabalho, houveram convenções que possuíam o escopo de igualar as condições de trabalho em todo o planeta inclusive o trabaIho da mulher. A Convenção oo 3 de 1919, ratificada pelo Brasil em 1934, garantia à mulher uma licença remunerada obrigatória de seis semanas antes e depois do parto. E, estabeleceu dois intervalos de 30 minutos para a amamentação, além do mais, previa ser ilegal a dispensa da trabalhadora durante a gravidez ou durante a referida licença.

A Convenção de $n^{\circ} 4$ da OIT, foi igualmente ratificada pelo Brasil e também trouxe alterações para o trabalho feminino. Esta vedou o labor noturno das empregadas em indústrias tanto públicas, quanto privadas. Entretanto, obreiras que trabalhavam em lugares onde haviam apenas membros da família, não possuíam tal restrição.

Apesar de muitos direitos ainda ausentes, a mudança de paradigmas com as referidas normas foi, naquela oportunidade e ainda 
contemporaneamente, o começo de uma proteção legislativa ao trabalho feminino e, apesar da pouca aplicabilidade das referidas normas, com elas já podia-se pensar em garantias trabalhistas à mão-de-obra feminina.

Contudo, devido ao desafio da efetividade normativa, ainda havia uma explícita disparidade entre os sexos. Para Piovesan (2003, p. 39), a efetivação dos direitos fundamentais relaciona-se intimamente com a consolidação do Estado Democrático de Direito. Entretanto, o ordenamento jurídico brasileiro, até mais da metade do século $X X$, não reconhecia a mulher como titular de direitos e plenamente capaz de exercer os atos da vida civil; lamentavelmente, era vista perante a sociedade como um simples objeto de deleite masculino. Entretanto, surge no dia 27 de agosto de 1962 a Lei n. 4.121, o "Estatuto da Mulher Casada", que permitia ao gênero feminino certas liberdades como o recebimento da herança, a compra e venda de imóveis e a dispensa de autorização do marido para trabaIhar fora de sua residência.

Felizmente, em 1984, o Brasil ratificou a Convenção sobre os Direitos da mulher. Esta vedava qualquer forma discriminatória entre os gêneros ampliando a atuação feminina no âmbito político, econômico, social e garantindo a esta classe uma sucessão de direitos fornecidos pelo Estado. Em tese, deveriam possuir igualdade perante a lei, direito ao voto, direito de exercer funções públicas em todos os níveis, direito ao trabalho e oportunidade de serviços nas mesmas condições que os homens, destaca assim Calil (2007, p. 2).

Como elemento construtor da cidadania, imperioso se faz definir o percurso feminino até atingir pleno acesso ao sufrágio, assim o direito ao voto foi conquistado paulatinamente, iniciando em 3 de maio de 1933, na Assembleia Nacional Constituinte, a mulher brasileira pôde finalmente em âmbito nacional votar e ser votada. 
Assim apenas em 1934, na segunda Constituição da República Federativa do Brasil, os direitos políticos conferidos às mulheres estiveram previstos em texto constitucional como descreve Lenza (2014, p. 133 e 134). E mais uma vez, havia restrição de voto àquelas que exerciam funções públicas remuneradas.

Finalmente, segundo o glossário eleitoral do Tribunal Superior Eleitoral, com a Carta Magna de 1946, estava instaurado definitivamente o sufrágio feminino, não havendo nem que se especificar se os eleitores poderiam ser homens ou mulheres, mas exigindo apenas a idade mínima de 18 anos e o alistamento eleitoral. Ainda, conforme informações do mesmo Tribunal, foram 100 anos em busca desta conquista, já que as discussões acerca deste assunto se iniciaram em meados do Século XIX.

Apesar de muitos direitos ainda ausentes, era o começo de uma proteção legislativa ao sexo feminino e, apesar da pouca aplicabilidade e eficácia das recentes normas, já podia-se pensar em garantias trabalhistas à mão-de-obra feminina.

Erguendo o reconhecimento formal da igualdade entre homens e mulheres, a Carta Magna de 1988 em seu artigo 5o, em meio ao rol exemplificativo de direitos e garantias fundamentais prevê que:

Todos são iguais perante a lei, sem distinção de qualquer natureza, garantindo-se aos brasileiros e aos estrangeiros residentes no País à inviolabilidade do direito à vida, à liberdade, à igualdade, à segurança e à propriedade, nos termos seguintes: I- homens e mulheres são iguais em direitos e obrigações, nos termos desta Constituição.

O referido texto constitucional, não se trata apenas de uma busca por instrumentos que garantam uma proteção contra a discriminação, mas o que se almeja são melhores condições para que a 
mulher possua ilimitadas oportunidades em uma sociedade culturalmente machista. Obviamente, não significa com esse clamor à igualdade o impedimento necessário no tratamento de algumas diferenças, sejam utilizados em razão do gênero, mas que sejam pautados em grau de razoabilidade e proporcionalidade. Como preleciona Yanoulas (2006, p.62), o dever do Estado neste espaço social consiste em favorecer um diálogo social a ponto de combater de forma inegociável os diversos tipos de discriminação para garantir o exercício pleno da cidadania.

\section{A dignidade humana como paradigma legal e o advento da consolidação das leis do trabalho}

Sabe-se que para uma real eficácia nos processos políticosociais é preciso haver a valorização da dignidade humana. Articular os direitos humanos implica valores que possam abranger todos os grupos sociais. O pluralismo é o que condiciona o modelo democrático brasileiro. As diferenças são parte do contexto social e o respeito a elas é primordial para que haja desenvolvimento e proteção às minorias e aos grupos vulneráveis. Conforme preleciona Sarlet (2007):

A dignidade da pessoa humana, sem prejuízo de sua dimensão ontológica e, de certa forma, justamente em razão de se tratar do valor próprio de cada uma e de todas as pessoas, apenas faz sentido no âmbito da intersubjetividade e da pluralidade. Aliás, também por esta razão é que se impõe o seu reconhecimento e proteção pela ordem jurídica, que deve zelar para que todos recebam igual consideração e respeito por parte do Estado e da comunidade [...]. (p.317) 
Apesar da dignidade da pessoa humana, apresentar-se como princípio Constitucional positivado no fundamento do Estado Democrático de Direito vigente, da Silva (2000, p. 147) anuncia que em face da ordem constitucional brasileira, "já não é princípio constitucional fundamental, mas valor supremo e fundante de toda a ordem jurídica, social e política". Infelizmente, estes conceitos não se faziam presentes em períodos mais remotos da legislação brasileira.

A dignidade da pessoa humana é uma construção natural do direito, afeta os direitos humanos e direitos fundamentais essencialmente, nessa formação a autora Barcellos (2008), com base nos ensinamentos de José Carlos Vieira de Andrade declara:

Realmente, o princípio da dignidade da pessoa humana está na base de todos os direitos constitucionalmente consagrados, quer dos direitos e liberdades tradicionais, quer dos direitos de participação política, quer dos direitos dos trabalhadores e direitos a prestação sociais. (p.128)

Essa construção democrática da dignidade não somente edifica um Estado onde o cidadão tem elemento central em sua formação, mas especialmente uma vertente reformulada da realidade já vivida historicamente, com isso o autor John Rawl (1992) estabelece que:

O primeiro princípio, o da igual liberdade para todos, constitui o padrão primário para a convenção constituinte (...) Assim, a Constituição estabelece e protege um estatuto comum da igualdade entre os cidadãos e realiza a justiça no plano político. O segundo princípio intervém na etapa legislativa. Obriga a que as políticas económicas e sociais se orientem para a maximização das expectativas a longo prazo dos menos favo- 
recidos, respeitando as condições da igualdade equitativa de oportunidades e mantendo as liberdades iguais para todos. (p.218)

A construção de uma constituição baseada fundamentalmente no princípio da dignidade da pessoa humana, efetiva o Estado brasileiro com constituto da vontade humana, do trabalho sobre o ser humano em primeiro plano e como primeira geração de seus objetivos. Na verdade, tal estruturação ocorre não apenas por um interesse político, mas com fundamento em teorias internacionais de Direitos Humanos, tendo em vista que a segunda grande guerra não foi somente um momento de expansão feminina, mas especialmente a fundamentação de uma realidade onde o ser humano perdeu seu valor em si, iniciando assim uma jornada através das Constituições mundo afora, na busca da valorização do ser humano, trazendo na sua fundamentação a qualificação do ser como fonte principal de existência do Estado, e não o inverso, ou seja, sendo o ser humano utilizado para a construção de um Estado.

Desta forma, com o objetivo de estabelecer uma Constituição forte e aguerrida nos interesses do ser humano como fonte principal de sua estrutura, os princípios fundamentais do Estado Democrático de Direito, tem a dignidade da pessoa humana, o valor do trabalho, a cidadania, como estruturas de base de sua construção, ou seja, dos cinco elementos que constituem os fundamentos do texto constitucional, três são exclusivamente dirigidos ao cidadão, ao povo, sendo nacional ou internacional.

Retrospectivamente, a Constituição de 1824, prestigiou a liberdade do exercício profissional. Anos mais tarde, a Carta Republicana de 1891 passou a garantir a liberdade de associação prevendo "o livre exercício de qualquer profissão moral, intelectual e industri- 
al", como leciona Lenza (2014, p. 127). Entretanto, a discriminação feminina ainda era um obstáculo para o desenvolvimento e bemestar social e familiar, pois dificultava-se a participação da mulher na prestação de serviços em geral.

Nestes termos, no ano de 1943, através do Decreto-lei no 5.452, institui-se a mais significativa norma trabalhista conhecida como Consolidação das Leis do Trabalho (CLT) vigente até os dias atuais. Esta resguarda em seu Capítulo III a "Proteção ao Trabalho da Mulher" a partir do artigo 372, prevê normas acerca da duração do trabalho, das condições e da discriminação contra a mulher, como descreve Biavaschi, Fuchina, Luz (2009, p. 11). Além disso, aborda o trabalho noturno, os períodos de descanso, os métodos e locais de trabalho, a proteção à maternidade como também as penalidades à infração de qualquer dispositivo deste Capítulo.

Em relação à saúde, a CLT vedou a realização de horas extras sem um atestado médico que autorizasse como também restringiu a força muscular superior a 20 quilos em trabalhos habituais, e vinte e cinco quilos para trabalhos eventuais. Tais restrições proporcionavam uma melhor qualidade de vida à mulher, e menor possibilidade de adoecer devido a grandes esforços.

Além da saúde, normatizou-se o trabalho noturno feminino, com isso, não apenas garantia-lhe proteção à saúde, como também a sua moral; pois mulheres que trabalhavam à noite poderiam ser vistas como imorais pela sociedade, ou seja, ao mesmo tempo que se estabelecia avanços, as construções morais onde a mulher não é ser completo postergavam nas normas. Cabe observar neste ponto, fortes vestígios de uma nação machista e preconceituosa que prejudica ainda mais o acesso da mulher a ambientes que possuem trabalhos noturnos como restaurantes, bares, dentre outros. Constata-se que além das supracitadas normas, havia a proteção à mater- 
nidade que promovia garantias a saúde da gestante como também da criança gerada.

Infelizmente, todo este rol protetivo era visto como uma restrição ainda maior a mulher no mercado de trabalho. Subentendia-se que a contratação da mão-de-obra feminina seria um "peso", um "prejuízo" para seus patrões, fazendo com que os contratantes tivessem obrigados a cumprir tantas regras e normas que poderiam sofrer danos em sua renda ao invés de lucro. Enquanto, conforme Calil (2007, p. 3), na contratação de trabalhadores do sexo masculino, não haveriam que se preocupar com direitos sociais.

Apesar de todo o relato de construção e reconstrução dos direitos femininos laborais e consequentemente a um acesso irrestrito da cidadania, assim como diante da constatação de que a mulher seria um fardo na contratação, surge na construção das regras da Consolidação das Leis do Trabalho, o questionamento sobre a redução salarial sendo absurdo diferenciar o valor do provento feminino do masculino, desta forma, neste contexto, a CLT abarcou a isonomia salarial entre homens e mulheres contrariando aqueles que entendiam ser o trabalho feminino oneroso por si só.

Toda essa efetividade de normas, essa construção da dignidade no meio trabalhista, ocorre especialmente quando a proposta inicial da dignidade está concretamente presente, nem exacerbadamente no protecionismo desnecessário, nem muito menos no esquecimento ou na omissão em seu cumprimento. O dever do Estado nesse intrínseco jogo de direitos é buscar meios e caminhos equilibrados para fazer com que o direito ao exercício profissional e da igualdade feminina se encontrem presentes e protegidos na realidade do Estado Democrático de Direito.

No entanto, muito embora muitas normas tenham sido produzidas até o momento, o caminho da efetividade na conquista desses Rev. Elet. Cient. UERGS, v. 3, n. 3, p. 472-494, 2017 
direitos ainda não foi plenamente efetivado. Pesquisa do Observatório Brasil da igualdade de Gênero, levanta o questionamento sobre a diferença salarial de gênero e constata:

As mulheres latino-americanas ganham menos, mesmo que possuam um maior nível de instrução. Por meio de comparação simples dos salários médios, foi constatado que os homens ganham $10 \%$ a mais que as mulheres. Já quando a comparação envolve homens e mulheres com a mesma idade e nível de instrução, essa diferença sobe para $17 \%$. Da mesma forma, a população indígena e negra ganha em média $28 \%$ menos que a população branca de mesma idade e nível de instrução.

Com isso, a percepção da necessidade de maior efetividade aos construtos normativos deveria ser objeto de políticas públicas inteligentes e efetivas, não bastando para tanto a criação normativa para produção de seus efeitos.

\section{Igualdade: a realidade da igualdade de gênero no es- tado democrático de direito sobre o prisma dos direi- tos humanos}

A Carta Magna de 1988, em seu artigo 5ํ, caput, apresenta a concepção de uma igualdade formal, aquela adquirida perante a Lei: "Todos são iguais perante a lei, sem distinção de qualquer natureza [...]". Entretanto, Moraes (2002, p. 65), descreve o Princípio da Igualdade operando em dois planos distintos:

De uma parte, frente ao legislador ou ao próprio Poder Executivo, na edição, respectivamente, de leis, atos normativos e medidas provisórias, impedindo que possam criar tratamentos 
abusivamente diferenciados a pessoas que se encontram em situação idêntica. Em outro plano, na obrigatoriedade ao intérprete, basicamente, a autoridade pública, de aplicar a lei e atos normativos de maneira igualitária, sem estabelecimento de diferenciações em razão de sexo, religião, convicções filosóficas ou políticas, raça e classe social.

Isso posto, é possível afirmar que a Igualdade na lei, sendo esta formal, indica uma vedação das normas jurídicas a produção de distinções, enquanto que a Igualdade perante a lei, material, compreende uma aplicação do direito em casos reais, de forma a garantir um tratamento igual para os iguais e desigual para os desiguais. Nas palavras de Nery Júnior (1999, p. 42): "Dar tratamento isonômico às partes significa tratar igualmente os iguais e desigualmente os desiguais, na exata medida de suas desigualdades".

Salienta esclarecer que não há que se buscar uma igualdade a ponto de enaltecer o que um sujeito já possui, e apenas suprir o que outro necessita. Segundo Bulos (2002, p.79): “ O raciocínio que orienta a compreensão do princípio da isonomia tem sentido objetivo: aquinhoar igualmente os iguais e desigualmente as situações desiguais". Desta forma, há que se falar em uma igualdade proporcional, que alcance de forma real o contexto no qual estejam os sujeitos inseridos. Na lição de Moares (2002, p. 58): “Assim, os tratamentos normativos diferenciados são compatíveis com a Constituição Federal quando verificada a existência de uma finalidade razoavelmente proporcional ao fim visado".

Entretanto, a realidade da igualdade de gênero no Estado Democrático de Direito traz uma certa disparidade entre as declarações trazidas pela Lei e a sua fatídica execução. Norberto Bobbio (2004, p.60) determina que "uma coisa é falar dos direitos do homem, direitos sempre novos e cada vez mais extensos, e justificá- 
los com argumentos convincentes; outra coisa é garantir-lhe uma proteção efetiva". Nestes termos, é insuficiente que a Lei Maior prelecione um rol exaustivo de direitos fundamentais se o Estado não corresponder a eles com plena aplicabilidade.

A ministra Luciana Lóssio, em voto sobre a participação da mulher em propaganda partidária no Recurso Especial Eleitoral de no 126-37.215.6.21.0000, do Rio Grande do Sul, expressamente ratificou a importância da presença feminina na política:

\begin{abstract}
A igualdade de gênero é um tema caro para a Justiça Eleitoral, devendo ser obrigatoriamente cumprido pelos partidos políticos, porquanto fundamental para o fortalecimento da democracia, que tem a igualdade como um dos pilares do Estado Democrático de Direito.
\end{abstract}

Para a ministra, o Brasil ainda não foi capaz de transferir para o plano prático o que prevê o plano teórico legal sobre a igualdade representativa de gênero. Ressaltou ainda que dos Poderes da República, o Legislativo é o único que ainda não foi presidido por uma mulher. Em termos finais, referenciou o Programa das Nações Unidas para o Desenvolvimento afirmando que os países que possuem o maior índice de desenvolvimento humano "são aqueles que possuem considerável representação feminina, por seu uma sociedade mais igualitária". Segue abaixo diferenciação sobre igualdade formal e material, traçado por Ikawa (2008, p. 150-152) na ADI 4277/DF.

O princípio formal de igualdade, aplicado com exclusividade, acarreta injustiças [...] ao desconsiderar diferenças em identidade.[...]

Apenas o princípio da igualdade material, prescrito como critério distributivo, percebe tanto aquela igualdade inicial, quanto essa diferença em identidade e contexto. Para respeitar a 
igualdade inicial em dignidade e a diferença, não basta, portanto, um princípio de igualdade formal. (IKAWA, 2008, p. 150-152)

Konrad Hesse (2009, p.42), ensina que "A busca pelo Estado da efetividade dos direitos fundamentais tornou-se precondição de que chegue a haver uma real liberdade". Não há que se falar em direitos humanos como simples normas fortalecidas constitucionalmente, representando um símbolo da liberdade social, mas "autênticos direitos positivados, com efetiva força jurídica” (MONTEIRO, 2013, p.144). Conforme ainda Hesse, desenvolveu-se a acepção de igualdade material da seguinte forma:

Igualdade jurídica material não consiste em um tratamento igual sem distinção de todos em todas as relações. Senão só aquilo que é igual deve ser tratado igualmente. O princípio da igualdade proíbe uma regulação desigual de fatos iguais; casos iguais devem encontrar regra igual. A questão é quais fatos são iguais e, por isso, não devem ser regulados desigualmente. (HESSE apud GONÇALVES, 2013, p. 79).

No entanto, outro fator se faz imprescindível nesse deslinde: a compreensão da diferença entre uma igualdade formal e uma igualdade material, assim:

Igualdade jurídica formal é igualdade diante da lei [...]. Ela pede a realização, sem exceção, do direito existente, sem consideração da pessoa: cada um é, em forma igual, obrigado e autorizado pelas normalizações do direito e, ao contrário, é proibido a todas as autoridades estatais não aplicar direito existente em favor ou à custa de algumas pessoas. Nesse ponto, o mandamento da igualdade jurídica deixa-se fixar, 
sem dificuldades, como postulado fundamental do estado de direito (HESSE apud GONÇALVES, 2013, p. 79).

Neste ínterim de efetividade dos direitos fundamentais, há que se explorar acerca dos Direitos da Personalidade. A partir do Direito à Vida, sendo este o mais fundamental dos direitos, verificase um desdobramento ao Princípio da Dignidade Humana. Pois em união estão o direito de continuar vivo e o direito de ter uma vida digna quanto a subsistência. Farias (1996, p.47) acrescenta:

O Princípio Constitucional da dignidade da pessoa humana refere-se às exigências básicas do ser humano no sentido de que ao homem concreto sejam oferecidos recursos de que dispõe a sociedade para a mantença de uma existência digna, bem como propiciadas as condições indispensáveis para o desenvolvimento de suas potencialidades.

Observa-se contraditório falar em condições para o desenvolvimento de potencialidades quando ainda há restrições quanto ao gênero feminino no ambiente laboral. A liberdade da mulher se desenvolver e alcançar sua realização profissional, carece de atenção no que tange a respeitabilidade do Estado Democrático de Direito, pois a igualdade de gêneros só velará pelos Direitos Humanos quando realmente vivenciada.

Os direitos humanos são fundamentais na construção de uma nova realidade de direitos e na construção de uma contemporaneidade mais afeta aos interesses humanos e menos fortalecedora da vontade do Estado. No entanto, a necessidade de uma organização estatal forte e bem estruturada é fundamental para a efetividade de direitos, uma sociedade com educação de qualidade forta- 
lece a construção de direitos, não por acaso há estudos que definem que toda entidade familiar em que a mulher tem nível mais elevado de educação seus filhos também terão, tudo isso trará uma construção social que passa pela certeza de que deveres e direitos serão observados.

Os direitos fundamentais desta feita são, nada mais que a constitucionalização dos direitos humanos, na certeza de que o cidadão poderá cobra-lo do Estado e de outros indivíduos de sua sociedade. Além disso, sabe-se que a dignidade é afeta de várias estruturas sociais e econômicas, boa condição de vida proveniente de um trabalho digno é algo fundamental, especialmente para a mulher do século $X X I$, assim efetivar políticas que propiciem à mulher a igualdade de condição no trabalho não somente é importante à economia, mas à sociedade como um todo, assim como sua participação em todas as atividades atinentes a construção da cidadania, como muito se necessita, na realidade política do país, onde as cotas de mulheres são exigidas, mas não são efetivas, a mulher ainda não é realidade na estrutura política. $O$ objetivo é entender as necessidades que precisam ser atacadas, não somente por uma política que construa a igualdade, mas por uma sociedade que se conscientiza da importância de sua efetividade.

\section{Considerações Finais}

A evolução política e social do trabalho da mulher trouxe diversas conquistas para o gênero. Houve crescente participação da presença feminina no mercado de trabalho, a mulher tornou-se destaque na educação e como consequência atingiu cargos e profis- 
sões de prestígio que anteriormente eram classificados como exclusivamente masculinos.

Entretanto, Apesar da evolução feminina no mercado de trabalho, a igualdade de gênero no ambiente laboral necessita de aprimoramento e estímulo por parte do Estado com base na dualidade "Democrático de Direito". Não haverá efetividade se as normas garantidoras e protetoras dos Direitos Humanos estiverem apenas como "folha de papel", assim como leciona o teórico Ferdinand Lassale. É preciso que o Estado desenvolva condições para que esta igualdade seja real.

Neste ínterim, verifica-se a evolução da mulher no ercado de trabalho como uma libertação a antigos dogmas. Atualmente, faz-se possível uma discricionária opção pelo curso de graduação, pela profissão a ser seguida, pelo casamento ou pela ausência dele e até mesmo a escolha pelo número de filhos ou por abster-se de tê-los. É atingindo no contexto fático a liberdade de escolhas individuais e profissionais que a aplicação dos direitos inerentes ao gênero feminino estará garantindo, a real igualdade material almejada.

A efetividade normativa ocorre quando a dignidade da muIher no ambiente trabalhista, político, social, venha tornar-se uma realidade de forma proporcionalmente igualitária, e não apenas em números para atingir um coeficiente meramente especulatório e necessário para cumprir norma. Tal fato não deve retirar da mulher sua independência e capacidade de desenvolvimento por uma proteção exacerbada, muito menos deixando-a desamparada de seus direitos fundamentais. O Estado Democrático de Direito precisa assumir a Dignidade da Pessoa Humana como paradigma existencial, de forma a garantir tratamento isonômico no que tange a real igualdade de gênero no ambiente de trabalho, de forma equilibrada, dentro das desigualdades existentes, mas sem trazer à mulher um pa- 
ternalismo não condizente com sua capacidade, pois mulher alguma é incapaz de chegar ou fazer o que necessário for, basta apenas não impedir e deixa-la fazer.

\section{Referências}

BARCELLOS. A Eficácia Jurídica dos Princípios Constitucionais: o princípio da dignidade da Pessoa Humana. 2 ed. Rio de Janeiro: Renovar, 2008.

BARROS, A. M. A Mulher e o Direito do Trabalho. São Paulo: LTr, 1995.

BOBBIO, N. A Era dos Direitos. São Paulo: Campus, 2004.

BRASIL. Constituição da República Federativa do Brasil, 5 de outubro de 1988. 18 ed. atual e ampl. São Paulo: Saraiva, 2014.

. Tribunal Superior Eleitoral. Recurso Especial Eleitoral no 126-37.2015.6.21.0000, do Estado do Rio Grande do Sul. Disponível

em:

<http://www.migalhas.com.br/arquivos/2016/9/art20160923-10.pdf>. Acesso em: 20 set 2016.

Superior Tribunal Eleitoral. Há 80 anos as mulheres conquistaram o direito de votar e ser votadas. Disponível: http://www.tse.jus.br/imprensa/noticias-tse/2013/Marco/ha-80-anosmulheres-conquistaram-o-direito-de-votar-e-ser-votadas>. Acesso em: 17 set 2016.

Supremo Tribunal Federal. Ação Direta de Inconstitucionalidade número 4277/DF.

BULOS, U. L. Constituição Federal anotada. São Paulo: Saraiva, 2002. 
CALIL, L. E. S. Direito do trabalho da mulher: ontem e hoje. In: Âmbito Jurídico, Rio Grande, X, n. 40, abr 2007. Disponível em: $<$ https://goo.gl/1erHqP>. Acesso em set 2016.

COSTA, F. N. Manual do Juiz do Trabalho. Salvador: Bahia, 2013.

FARIAS, E. P. de. Colisão de Direitos. A honra, a intimidade, a vida privada e a imagem versus a liberdade de expressão e informação. Porto Alegre: Sérgio Antônio Fabris Editor, 1996.

FUCHINA, R.; LUZ, A. F. da. A evolução Histórica dos Direitos da Mulher Sob a Ótica do Direito do Trabalho. Anais... do II Seminário Nacional de Ciência Política da UFRGS, 2009. Disponível em: $<$ http://www.ufrgs.br/nucleomulher/arquivos/artigoalex.pdf $>$. Acesso em 23 set 2016.

HESSE, K. Significado dos Direitos Humanos Fundamentais. In: ALMEIDA, Carlos dos Santos; MENDES, Gilmar Ferreira; COELHO, Inocêncio Mártires. Temas Fundamentais do Direito Constitucional. São Paulo: Saraiva, 2009.

LASSALE, F. O Que é Uma Constituição? 4. ed. Rio de Janeiro: Lúmen Júris, 1998.

LENZA, P. Direito Constitucional Esquematizado. 18 ed. São Paulo: Saraiva, 2014.

MONTEIRO, R. C. de A. Direitos Fundamentais Sociais: o desafio da efetividade e a instrumentalidade da ADPF. Curitiba: Juruá, 2013.

MORAES, A. de. Direito constitucional. São Paulo: Atlas, 2002.

NERY JÚNIOR, N. Princípios do processo civil à luz da Constituição Federal. São Paulo: Revista dos Tribunais, 1999.

OBSERVATÓRIO BRASIL DA IGUALDADE DE GÊNERO. Homens Recebem Salários 30\% Maiores Que As Mulheres No Brasil. Disponível em: https://goo.gl/Faj9fVAcesso em 14 mar. 2017. 
PIOVESAN, F. Direitos humanos e o princípio da dignidade humana. Revista do Advogado, São Paulo, Ano XXIII, no 70, julho de 2003, p. 34-42.

PORTO, W. C. Dicionário do voto. Brasília: UnB, 2000. p. 427-436.

RAWLS, J. Liberalismo Político. Trad. Sergio René Madero Báez. México: Fondo de Cultura Económica, 1992.

SARLET, I. W. (Org.) As dimensões da dignidade da pessoa humana: construindo uma compreensão jurídico-constitucional necessária e possível: ensaios de Filosofia do Direito e Direito Constitucional. Revista Brasileira de Direito Constitucional RBDC, São Paulo, n. 09, p. 371, jan. /jun. 2007.

SILVA, G. C. C. da et al . A mulher e sua posição na sociedade: da antiguidade aos dias atuais. Rev. SBPH, Rio de Janeiro, v. 8, n. 2, p. 65-76, dez. 2005. Disponível em: https://goo.gl/4ByZgY. Acesso em 17 set. 2016.

SILVA, J. A. Poder constituinte e poder popular: estudos sobre a constituição. São Paulo: Malheiros, 2000.

SILVA, M. B. N. da. Transmissão, conservação e fusão cultural no Rio de Janeiro (1808-1821). Revista de História da USP, vol. XLVII, n.97, jan./ mar. 1974. pp.154-159

YANOULAS, S. C. Seminário Internacional GRPE 2006 OIT/Brasil: Mesa Diversidade Texto Silvia C.Yannoulas Brasília, 28 de junho de 2006. 